MATEC Web of Conferences 47, 04008 (2016)

DOI: $10.1051 /$ matecconf/20164704008

CC Owned by the authors, published by EDP Sciences, 2016

\title{
Prediction of Low Cost Housing Demand in Malaysia Using ARIMA Model
}

\author{
N. Y. Zainun ${ }^{1, a}$, F. E. Mohamed Ghazali ${ }^{2}$ and M. S. Mohd Sallehudin ${ }^{1}$ \\ ${ }^{1}$ Faculty of Civil and Environmental Engineering, University Tun Hussein Onn Malaysia, 86400 Parit Raja, Johor, \\ Malaysia \\ ${ }^{2}$ School of Civil Engineering, University Sains Malaysia, 14300 Nibong Tebal, Pulau Pinang, Malaysia
}

\begin{abstract}
Among the key challenges in construction industry sector faces are matching supply of and demand for affordable housing. It is very crucial to predict low-cost housing demand to match the demand and supply so that the government can plan the allocation of low cost housing based on the demand. In Johor, housing provision is very crucial due to urbanization. The supply of houses seems to be swamping the demand for luxury condos and houses especially in Johor Bharu. Thus the aim of this study is to predict low-cost housing demand in Johor, Malaysia using ARIMA model. Time series data on low-cost housing demand have been converted to Ln before develop the model. The actual data and forecasted data will be compared and validate using Mean Absolute Percentage Error (MAPE). After that, the results using ARIMA method will be compared with ANN method. The results show that MAPE analysis for ARIMA is $15.39 \%$ while ANN is $18.27 \%$. It can be conclude that ARIMA model can forecast low cost housing demand in Johor quite good.
\end{abstract}

\section{Introduction}

One of Malaysia's longstanding development objectives is the provision of affordable housing for Malaysian, with a focus on lower-income groups [1]. Low cost housing can be defined as a development projects sold at the price set by the government that is between RM25, 000 to RM42, 000 [2]. Low cost housing built is intended to provide housing that is affordable for low earners in rural and suburban areas. The target groups for this project are households with monthly income of between RM500 to RM750 [3].

To provide adequate housing and affordable for Malaysians, especially for those with low incomes has become the main agenda through Malaysia plans prior to now [4]. However, there is mismatched data between the supply and demand for low-cost housing in Malaysia [5]. In some places, the supplies of low cost housing are exceeding compare to demand and lead to wastage of construction and of course has an impact on the cost and economic aspects. While in other areas the demand is exceeding supply provided, which supplies low-cost houses are insufficient, especially in urban areas [6]. Therefore, an alternative approaches need to be done to resolve these issues.

There are many series of forecasting methods can be used to predict the housing demand such as Artificial Neural Network (ANN), Autoregressive Integrated Moving Average (ARIMA), Power

\footnotetext{
${ }^{a}$ Corresponding author : nryasmin@uthm.edu.my
} 
Model and Multiple Log linear Regression [7]. In this study ARIMA model known as the Box-Jenkins time series is used because it has good accuracy for the short term forecasting.

\section{Scope and Limitation of Study}

This study will focuses on forecasting low cost housing demand in Johor, Malaysia only. Previous time series data from [6] will be used to forecast low-cost housing demand in Johor using ARIMA model.

\section{Methodology}

The time series data were changed to Ln then analyzed using ARIMA software adopted from SPSS 20.0. Results were validated using MAPE where actual and forecasted data were compared to determine the accuracy of the model. Finally, the MAPE value will be compared to establish the performance of model.

\section{Results and Discussion}

Table 1 shows the monthly time series data on low cost housing demand in Johor from January 2000 to January 2007.

Table 1. Time series data on low cost housing demand.

\begin{tabular}{|c|c|c|c|c|c|c|c|c|c|c|c|c|c|}
\hline $\begin{array}{c}\text { Month } \\
\text { Year }\end{array}$ & Jan & Feb & Mac & Apr & May & Jun & Jul & Aug & Sept & Oct & Nov & Dec & Total \\
\hline 2000 & 90 & 272 & 360 & 325 & 360 & 405 & 497 & 488 & 334 & 474 & 472 & 530 & 4607 \\
\hline 2001 & 419 & 485 & 572 & 661 & 1005 & 544 & 544 & 434 & 318 & 550 & 555 & 356 & 6443 \\
\hline 2002 & 614 & 343 & 546 & 416 & 566 & 529 & 445 & 544 & 398 & 415 & 482 & 209 & 5507 \\
\hline 2003 & 404 & 477 & 424 & 312 & 299 & 414 & 365 & 498 & 280 & 269 & 211 & 264 & 4217 \\
\hline 2004 & 262 & 299 & 283 & 230 & 235 & 303 & 533 & 233 & 215 & 227 & 246 & 303 & 3369 \\
\hline 2005 & 243 & 182 & 230 & 205 & 232 & 180 & 188 & 166 & 209 & 196 & 121 & 210 & 2362 \\
\hline 2006 & 170 & 140 & 223 & 174 & 190 & 199 & 275 & 308 & 259 & 134 & 197 & 197 & 2466 \\
\hline 2007 & 157 & & & & & & & & & & & & 157 \\
\hline Total & 2359 & 2198 & 2638 & 2323 & 2887 & 2574 & 2847 & 2671 & 2013 & 2265 & 2284 & 2069 & 29128 \\
\hline
\end{tabular}

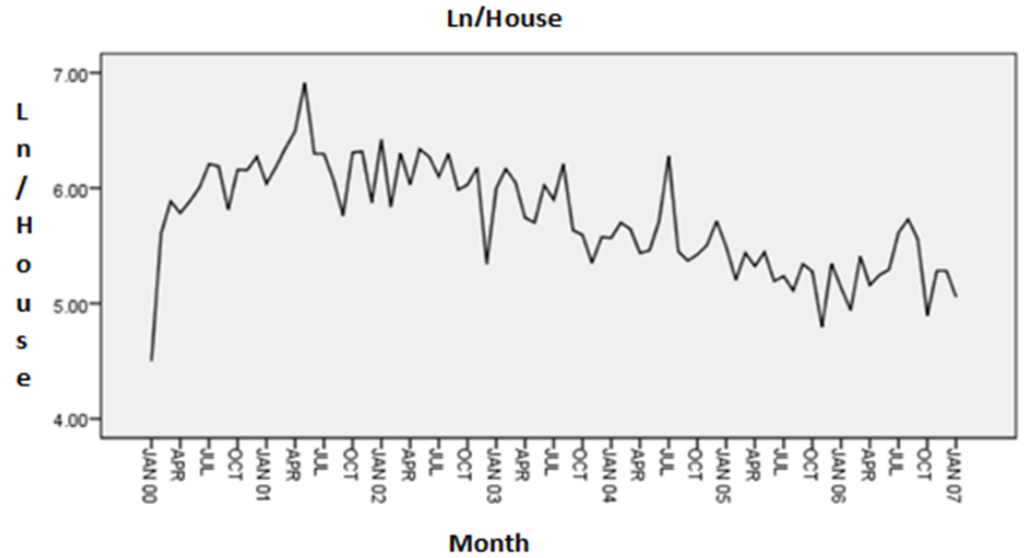

Figure 1. Housing demand (Ln). 
Figure 1 are time series housing demand in Ln. Data were change to Ln to get idea for $p, d$, q value for a non seasonal ARIMA model ARIMA (p, d, q), where $p$ is the number of autoregressive terms, $d$ is the number of nonseasonal differences needed for stationarity, and $\mathrm{q}$ is the number of lagged forecast errors in the prediction equation. $\mathrm{p}$ and $\mathrm{d}$ were determined using coefficient Auto Correlation (AC) and Partial Auto Correlation (PAC) where AR(p) and MA(q) are the components for the time series.

Figure 2 views the ACF and PACF of housing demand using ARIMA $(0,0,0)$. It can be seen that there are a few extrusions and improvements were done to create stationary data. From the p,d,q value, significant calculations for each parameters were done to determine the best model. In this study, three model were used; ARIMA $(1,0,1)$; ARIMA $(1,0,0)$ and ARIMA $(2,0,0)$. ARIMA model produced the lowest value Akaike Information Criterion (AIC) and Schwarz Criterion (SC) is the best model.

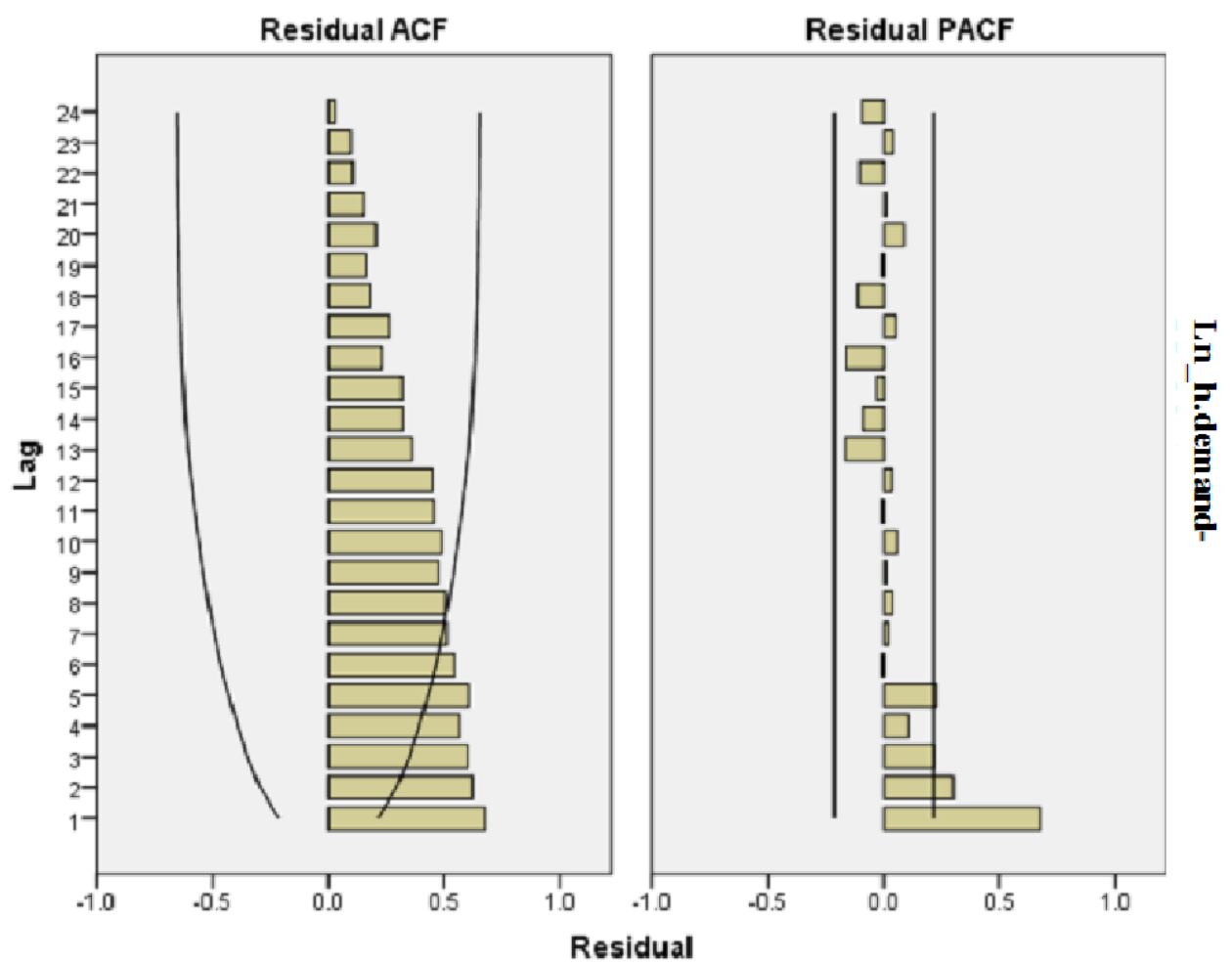

Figure 2. ACF and PACF of housing demand using ARIMA $(0,0,0)$.

Table 2 views the AIC and SC value for each ARIMA model. It can be seen that model ARIMA $(1,0,1)$ is the best compare to ARIMA $(1,0,0)$ and ARIMA $(2,0,0)$.

Table 2. Value for AIC and SC for each model.

\begin{tabular}{|c|c|c|}
\hline Model & AIC & SC \\
\hline ARIMA $(1,0,1)$ & 0.0178 & 0.2288 \\
\hline ARIMA $(1,0,0)$ & 0.0370 & 0.2499 \\
\hline ARIMA $(2,0,0)$ & 0.0656 & 0.2239 \\
\hline
\end{tabular}


Figure 3 plots the improve ACF and PACF using ARIMA $(1,0,1)$ and Table 3 shows the analysis value from model ARIMA $(1,0,1)$.

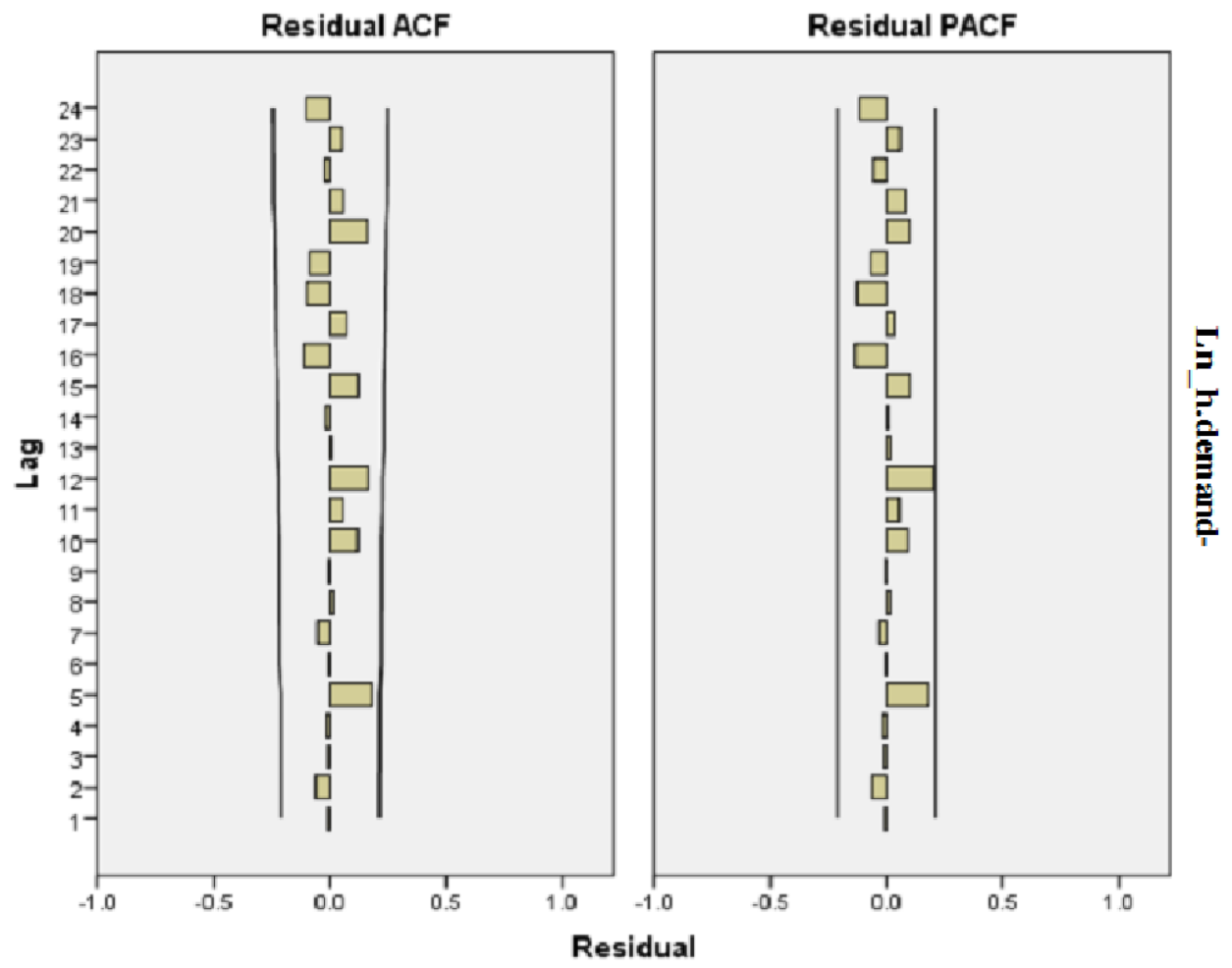

Figure 3. ACF and PACF of housing demand using ARIMA $(1,0,1)$.

Table 3. Analysis value for model ARIMA $(1,0,1)$.

\begin{tabular}{|c|c|c|c|c|}
\hline & Intersection & AR(1) & Variable (1) & MA(1) \\
\hline Coefficients & 10.2767 & 0.6014 & -0.0002 & -0.4317 \\
\hline Standard Error & 1.8472 & 0.0767 & 0.0000 & 0.1283 \\
\hline t-Statistic & 5.5634 & 7.8451 & -5.4500 & -3.3625 \\
\hline p-Value & 0.0000 & 0.0000 & & \\
\hline
\end{tabular}

From Table 3, $\mid$ tcalc $\mid>$ ttable $(=2.25)$ and $p$ less than alpha. Therefore, null hypothesis can be rejected and can be concluded that the coefficient is different from zero.

Table 4. Comparison forecasting value between tentative models.

\begin{tabular}{|c|c|c|c|c|}
\hline Month & Actual Data & ARIMA (1,0,1) & ARIMA (1,0,0) & ARIMA (2,0,0) \\
\hline September 2006 & 5.56 & 5.54 & 5.68 & 5.71 \\
\hline Oktober 2006 & 4.90 & 5.54 & 5.62 & 5.58 \\
\hline November 2006 & 5.28 & 5.31 & 5.23 & 5.09 \\
\hline Disember 2006 & 5.28 & 5.31 & 5.23 & 5.38 \\
\hline Januari 2007 & 5.06 & 5.31 & 5.23 & 5.39 \\
\hline MAPE & - & 3.90 & 4.42 & 5.72 \\
\hline
\end{tabular}

Table 4 is the comparison forecasting value between tentative models ARIMA. It shows that ARIMA $(1,0,1)$ have the lowest MAPE with 3.9\%. 
Therefore, the regression model equation was rewritten:

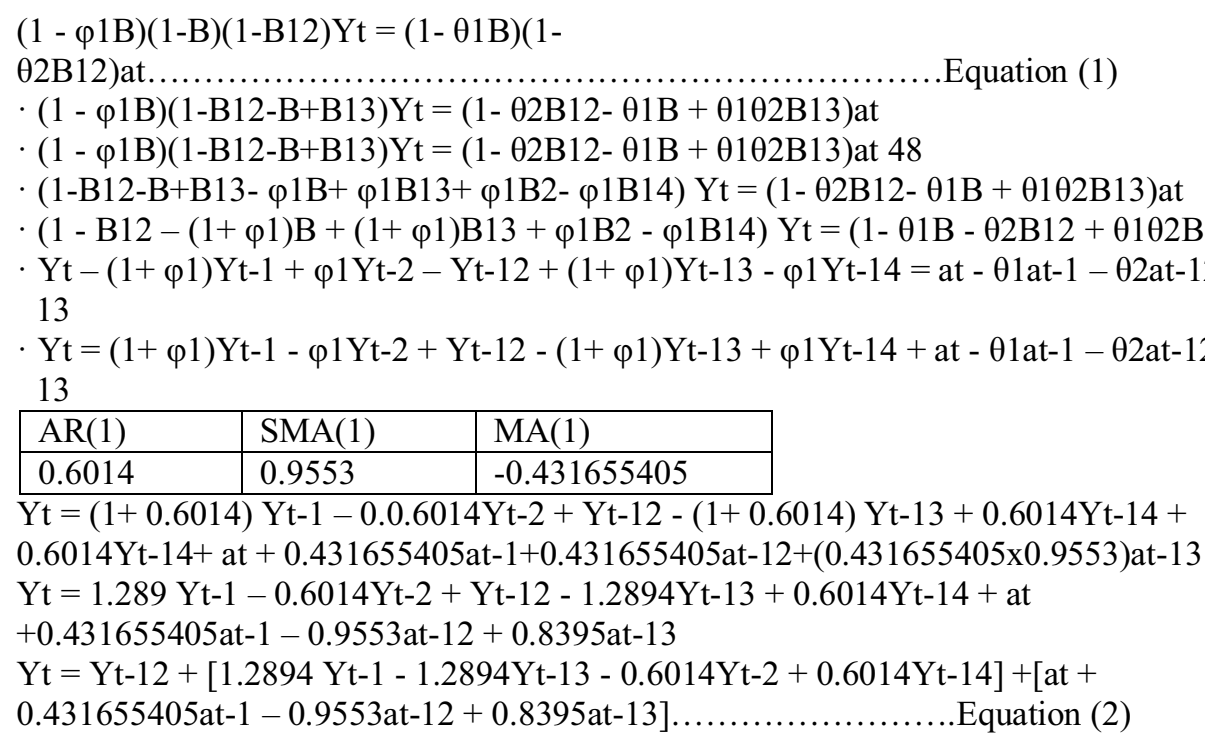

Therefore, Equation (2) is the ARIMA model to predict low-cost housing demand in Johor.

Table 5. The actual data and forecast data using ARIMA $(1,0,1)$ method.

\begin{tabular}{|c|c|c|c|c|}
\hline Time series & Actual & Forecasted & Actual - Forecasted & Percentage Error \\
\hline June 2006 & 199 & 191 & 8 & 4.02 \\
\hline July 2006 & 275 & 196 & 79 & 28.73 \\
\hline August 06 & 308 & 124 & 84 & 27.27 \\
\hline September 06 & 259 & 255 & 4 & 1.54 \\
\hline MAPE & & 15.39 \\
\hline
\end{tabular}

Table 5 shows the actual and forecasted data from June 2000 to September 2006 using ARIMA $(1,0,1)$ model. From the calculations, MAPE value obtained was $15.39 \%$. Predictive ability is very good if the MAPE is less than $10 \%$ while MAPE less than $20 \%$ is good [8]. The results show that MAPE value for ARIMA less than $20 \%$.

\section{Conclusion}

Since the MAPE value is less than $20 \%$, it can be conclude that ARIMA model can predict low-cost housing demand in Johor quite good. It is recommend further study should be done to reduce the error of performance since the results generated are able to assist the construction of low-cost housing scheme in terms of the accuracy of necessity based on actual demand. Subsequently there would be a minimal possibility of the procurement of either under-construction or over construction of low cost houses particularly in the state of Johor.

\section{References}

[1] The Tenth Malaysia Plan, (2011-2015), Economic Planning Unit, Prime Minister's Department, Putrajaya, (2010). 


\section{MATEC Web of Conferences}

[2] Ministry of Housing and Local Government Malaysia, Guidelines for the Implementation of the New Price of Low Cost Housing (Amendment) Act 2002, (2002).

[3] R. Mahamud and K. Hussein, Studies on potential medium income group in own homes in area Johor Bahru, University Technology Malaysia, Vote Upp, 71, 693, (2002).

[4] The Ninth Malaysia Plan (2006-2010), Chapter 21 Providing Housing and Urban Services Quality, Prime Minister's Department, Putrajaya, (2006).

[5] S. Shuid, Low medium cost housing in Malaysia: Issues and challenges, International Islamic University Malaysia, (2004).

[6] N.Y. Zainun, Computerized Forecasting Model to Forecast Low-Cost Housing Demand in Urban Area in Malaysia using Artificial Neural Networks (ANN), PhD Thesis, Loughborough University, (2012).

[7] N.Y. Zainun and M.Z. Abd Majid, Evolution on various forecasting models using artificial neural networks (ANN), Proc. of the 2nd International Conference on Innovation in Architecture, Engineering and Construction, United Kingdom, (2003).

[8] S. Harun, Forecasting and Simulation of Net Inflows for Reservoir Operation and Management, $\mathrm{PhD}$ Thesis, University Technology Malaysia, Johor, (1999). 